\title{
Cell cycle control by the Target of Rapamycin signalling pathway in plants
}

Zaki Ahmad ${ }^{1}$, Zoltán Magyar², László Bögre ${ }^{1}$, Csaba Papdi $^{1 *}$

1 School of Biological Sciences, Bourne Laboratory. Royal Holloway, University of London. TW20 0EX. Egham, Surrey. United Kingdom.

2 Institute of Plant Biology, Biological Research Centre, Hungarian Academy of Sciences Szeged, Hungary

${ }^{*}$ Corresponding author

(C) The Author(s) 2019. Published by Oxford University Press on behalf of the Society for Experimental Biology. All rights reserved. For permissions, please email:

journals.permissions@oup.com 


\section{Abstract}

Cells need to ensure a sufficient nutrient and energy supply before committing to proliferate. In response to positive mitogenic signals, such as light, sugar availability and hormones, the TARGET OF RAPAMYCIN (TOR) signalling pathway promotes cell growth that connects to the entry and passage through the cell division cycle via multiple signalling mechanisms. Here, we summarise current understanding of cell cycle regulation by the RBR-E2F regulatory hub and the DREAM-like complexes, and highlight possible functional relations between these regulators and TOR signalling. A genetic screen recently uncovered a downstream signalling component to TOR that regulates cell proliferation, YAK1, a member of the dual specificity tyrosine phosphorylation regulated kinase (DYRK) family. YAK1 activates the plant-specific SIAMESE-RELATED (SMR) cyclin-dependent kinase inhibitors and therefore could be important to regulate both CDKA-RBR-E2F pathway to control the G1/S and the mitotic CDKB1;1 to control the G2/M transitions. TOR, as a master regulator of both protein synthesis-driven cell growth and cell proliferation is also central for cell size homeostasis. We conclude the review by briefly highlighting the potential applications of combining TOR and cell cycle knowledge in context of ensuring future food security. 


\section{Introduction}

In plants, the cell cycle activity is concentrated in pools of undifferentiated cells, called meristems and this activity is the major driver for above- and below-ground organ growth (Gazquez and Beemster, 2017). Being energetically expensive, cell production, however, is limited by sugar availability and is dependent on sugar-sensing signalling pathways centred around the antagonistically acting Target of Rapamycin (TOR) and Sucrose Non-fermentingrelated kinase 1 (SnRK1; Dobrenel et al., 2016; Lastdrager et al., 2014; Rexin et al., 2015). In this review, we will discuss our current understanding on how light and sucrose regulates meristem activities through modulating the cell cycle. Because of the functional and structural conservation of both TOR pathway components and core cell cycle regulators, we will also highlight relevant yeast and animal literature to make a case for possible plant TOR and cell cycle connections.

TOR was discovered in budding yeast through the block of cell cycle progression in the G1 phase of the cell cycle upon treatment with rapamycin, a bacterial compound specifically targeting TOR. However, unlike mutants in genes controlling the cell cycle that continue to grow without cell division to become large, the rapamycin-treated yeast cells were small, leading to the original idea that TOR is a principal regulator of cell growth and through this indirectly effects cell cycle progression (Wang and Proud, 2009). Therefore, it is surprising that in plants TOR can directly regulate the expression of cell cycle genes and thus cell proliferation (Xiong et al., 2013). However, there is accumulating evidence that TOR as in other organisms, also regulates translation and through this meristem activity and cell proliferation (Schepetilnikov and Ryabova, 2018).

It is well accepted that growth drives cell cycle in many different organisms and being tightly connected to maintain cell size homeostasis (Amodeo and Skotheim, 2016; Wood and Nurse, 2015). The involvement of TOR in this process is evident in yeast, animal cells and might also be the case for plant meristematic cells, but the exact mechanism is not yet known (Sablowski and Carnier Dornelas, 2014). TOR is commonly considered to control the G1/S transition of the cell cycle but there is evidence specifically in the context of cell size homeostasis that it also acts through the G2/M control (Wood and Nurse, 2015). We will review the information available on sucrose and light control of the plant cell cycle to see how distinct cell cycle control points might be utilised. For general reviews on how plant relevant external conditions impact on plant physiology through the TOR signalling pathway, readers are referred to other excellent reviews (Dobrenel et al., 2016; Lastdrager et al., 2014; Rexin et al., 2015; Shi et al., 2018).

\section{TOR signalling promotes cell proliferation both in shoot and root meristems}

The Arabidopsis TOR-promoter::GUS transcriptional reporter is highly expressed in the primary meristem, but not in differentiated cells, indicating that TOR function is largely restricted to the meristematic region (Barrada et al., 2019; Menand et al., 2002). Both in TOR silenced plants and plants treated with TOR-specific ATP-competitive inhibitors e.g. AZD8055, there is a clear reduction in root and shoot growth. The dose-dependent inhibition of root growth by TOR inhibitors was traced back to the reduction of meristem size (Barrada et al., 2019; Montane and Menand, 2013; Xiong et al., 2013). This was done by measuring 
cell size profiles to determine the point where cells exit the cell cycle and start to elongate in the root meristem, by visualising mitotic cells using pCYCB1;1::destruction box-GUS reporter or by visualising cells in S-phase by EdU labelling. Thus, TOR regulates how long cells maintain the proliferation competence in the meristem before exiting to cell elongation and differentiation.

Both shoot and root growth are reliant on photosynthates and TOR-dependent activation of cell proliferation (Mohammed et al., 2018; Pfeiffer et al., 2016; Wu et al., 2019; Xiong et al., 2013). In the shoot, to maintain meristem activity, it was suggested that in addition to sugar, auxin biosynthesis is also required that is stimulated by blue and red light receptors and the COP1 signalosome to activate the TOR kinase Fig1A; (Chen et al., 2018; Li et al., 2017). The light, sugar and hormonal requirement for the activation of shoot meristem was also examined during the developmental transition of deetiolation (Chen et al., 2018; Mohammed et al., 2018). The dark-arrested meristem is under a state of energy deprivation accompanied by diffused auxin and non-membrane PIN1 localisation (Mohammed et al., 2018). The non-polar PIN1 localisation is instigated at least partly by the MKK7-MPK6 mitogen activated signalling module and the direct phosphorylation of PIN1 by MPK6 (Dóczi et al., 2019; Dory et al., 2018). Upon light exposure there is a rapid release of the starvation response, PIN1 expression is induced by light (Lopez-Juez et al., 2008) and becomes polar to remove auxin towards the growing leaf primordia (Dóczi et al., 2019; Mohammed et al., 2018). This is followed by the COP1 light signalling dependent induction of cell cycle- and protein translation-associated genes. For cell cycle regulation COP1 alters the balance between the activator E2FB and the repressor E2FC transcription factors (Berckmans et al., 2011; Lopez-Juez et al., 2008). The rapid and transient decline in the expression of auxin responsive genes e.g $A U X 1$ upon light exposure is not dependent on the photomorphogenesis program (Mohammed et al., 2018). Light requirement for leaf emergence can be bypassed in the dark by altering the auxin-cytokinin signalling balance, for example lowering the auxin response in the axr1, or increasing the cytokinin response in the arr1 mutants or by the exogenous supply of cytokinin or sucrose to the dark arrested shoot primordia (Braybrook and Kuhlemeier, 2010; Mohammed et al., 2018; Yoshida et al., 2011). This TOR-dependent sugar signal alone in the dark is perfectly capable to stimulate cell proliferation, but the development of a normal leaf lamina requires photomorphogenesislike hormonal responses (Mohammed et al., 2018).

It was shown that auxin signalling is relayed to TOR through Rho-related protein 2 (ROP2; a member of the Rho GTPase family; Li et al., 2017; Schepetilnikov et al., 2017). TOR activation promotes cell cycle entry by activating E2FA and E2FB transcription factors ( $\mathrm{Li}$ et al., 2017). The auxin induced ROP2-TOR pathway also plays important role in gene-specific translational control (Schepetilnikov et al., 2017; Schepetilnikov and Ryabova, 2017). The translationally controlled root and shoot meristem development and cell cycle target mRNAs by TOR are not yet established. In a physiological setting, TOR signalling has an important role to tune the extent of cell cycle activity and growth of young leaves non-cell autonomously under varying light irradiance (Mohammed et al., 2018).

Light and TOR signalling also regulate cell proliferation in singe-cell plants such as the green alga Chlamydomonas (Perez-Perez et al., 2017). The Chlamydomonas proliferates through a multiple-fission mechanism in which a long growth phase can precede multiple DNA replication rounds followed by multiple numbers of division, thereby producing two, four or 
eight daughter cells. The number of divisions normally depends on the light intensity and consequently the mother cell size (Bisova and Zachleder, 2014; Umen, 2018). The allosteric TOR inhibitor rapamycin suppressed division of Chlamydomonas, but increased the cell size at both early (within $1 \mathrm{~h}$ ) and later time-points (20h and 24h) after the treatment. Moreover, rapamycin delayed the onset of commitment point and mitosis, but interestingly not $S$ phase progression (Juppner et al., 2018). These results suggest that in Chlamydomonas TOR acts on important cell cycle regulatory transitions both in $\mathrm{G} 1 / \mathrm{S}$ and $\mathrm{G} 2 / \mathrm{M}$, as well as it regulates cell size. The principal regulator of the commitment point is the RBR gene; MAT3 in Chlamydomonas. CDKG1 was identified as an RBR kinase in this organism that determines the number of mitosis and consequent cell size in relation to mother cell size dictated by light (Li et al., 2016b; Umen, 2018). Based on the cell cycle outcomes of TOR inhibition, the CDKG1-MAT3 module represent a plausible signalling target for TOR to regulate these cell cycle transitions (Fig 2).

\section{Control of G1/S progression by the TOR pathway}

A conserved hallmark of commitment to enter the cell cycle is centred on the inactivation of a nuclear G1/S repressor, the Retinoblastoma protein (Rb), in plants called RB-RELATED (RBR). The inactivation occurs through phosphorylation by CDKA-CYCD complexes on multiple conserved residues of RBR, which results in the release of E2F-type transcription factors from RBR binding and allows for the transcription of genes required for DNA replication (Magyar et al., 2016).

In Arabidopsis, there is a single RBR-coding gene, and the rbr1 null-mutant alleles show gametophytic lethality, because the megagametophyte fails to arrest mitosis and undergoes excessive nuclear proliferation in the embryo sac (Ebel et al., 2004). Silencing of $R B R$ with RNA interference leads to continued proliferation and the lack of cellular differentiation in developing leaves (Borghi et al., 2010). Likewise, co-supression of $R B R$ (csRBR) due to the introduction of an extra copy, resulted in a complete growth arrest of Arabidopsis seedlings in nutrient limited conditions. At the same time, cells in developing cotyledons of csRBR seedlings showed gross over-proliferation when sucrose was supplemented in the growth medium (Gutzat et al., 2011). This raised the possibility for the existence of an unknown growth repressor independent or below RBR, which leads to the halt of cell proliferation in nutrient limited conditions.

Downstream of RBR, there are three E2F transcription factors (E2FA, E2FB and E2FC), which associate with one of the DIMERISATION PARTNER proteins (DPA or DPB) for DNA binding (Magyar, 2008). Mainly on the basis of overexpression studies, E2Fs can be categorised as activators (E2FA and B) or repressor-type (E2FC; Harashima and Sugimoto, 2016). In response to growth stimulating conditions, such as plant hormones or the available sugars, the abundance of particular G1 cyclin increases (Riou-Khamlichi et al., 2000). CYCD-CDKA;1 complexes then hyper-phosphorylate RBR on multiple conserved sites that leads to the release of activator E2Fs from RBR-binding to induce the expression of cellcycle genes (Magyar et al., 2012; Nakagami et al., 2002). In contrast, the repressor-type E2Fs function together with RBR to block cell proliferation. It is emerging that the separation into these two categories are sometimes blurred. For instance, the two E2Fs with positive 
roles in cell proliferation; E2FA and E2FB exhibit clear functional differences. When cell proliferation was induced by either applying exogenous sucrose or elevating CYCD3;1 levels, the complex formation between E2FB and RBR was disrupted due to RBR phosphorylation, however the interactions between E2FA and RBR were not weakened, but even further enhanced (Magyar et al., 2012). Based on ectopic expression studies, RBR-free E2FB regulates both G1/S and G2/M transition, and represses endoreduplication (Magyar et al., 2005; Sozzani et al., 2006). A recent in vivo phosphoproteomics analysis upon TOR inhibition uncovered that RBR phosphorylation on the CDKA sites are regulated by TOR activity. At the same time, E2Fs were not found to be TOR-dependently phosphorylated in this phosphoproteomics screen (Van Leene et al., 2019). In another recent study, it was shown that TOR inhibits the expression of SIAMESE-RELATED (SMR) cyclin-dependent kinase inhibitors through the YAK1 kinase (Fig1A; Barrada et al., 2019). Whether the TORdependent RBR phosphorylation by CDKA activity relies on changing cyclin or the opposing CDK inhibitor (CKI) abundance remains to be investigated.

The RBR-E2FA complex was shown to have a role in repressing endocycle genes (Fig1 A), such as CCS52A1 and CCS52A2 in the meristem, thus preventing premature exit of cells to the elongation zone and therefore maintaining a healthy pool of dividing cells (Magyar et al., 2012). It might be feasible that TOR phosphorylation on E2FA promotes the formation of such a repressor RBR-E2FA complex to increase meristem size and therefore organ growth in the presence of sucrose. It might also be possible that TOR only phosphorylates RBR-free E2FA, which promotes S-phase progression during mitotic cell cycle and endocycle when cells elongate (Xiong et al., 2013).

In response to glucose induction, TOR makes global transcriptome changes, including many S-phase regulatory genes (Xiong et al., 2013). It was shown that in Arabidopsis cells TOR is able to interact with E2FA and when immuno-precipitated from seedlings, TOR could in vitro phosphorylate the recombinant E2FA within a large region of its $\mathrm{N}$-terminus (1-80 amino acid), but the exact phosphorylation sites have not yet been determined (Xiong et al., 2013). Because a broad-spectrum S/T protein kinase inhibitor, staurosporine did not affect the TOR-dependent E2FA activation, it was also concluded that S6K is not required downstream of TOR for the activation of S-phase genes (Xiong et al., 2013). After deleting the 80aa Nterminal region, E2FA lost its transcriptional activity, but it is not clear whether such truncated E2FA retains its ability for DNA binding. In a similar experimental setup, TOR was also shown to phosphorylate E2FB (Li et al., 2017), even though the N-terminal domains and specifically the distribution of phosphorylation sites on E2FA and E2FB greatly differ from each other. It was further shown that TOR, E2FA and E2FB are all important to activate the root meristem of Arabidopsis plants from an experimentally-induced oxygen-deprived quiescent state. Based on the direct interaction and phosphorylation of E2FA and E2FB by TOR, it was proposed that the TOR-E2FA/B regulatory unit is independent of the canonical CDK-CYC-RBR route of cell cycle entry. It will be of importance to determine the exact phosphorylation sites on these E2F proteins and how these phosphorylation events regulate their functions in terms of DNA binding, transactivation of target genes, association with RBR and other regulatory proteins.

The Arabidopsis mutant line, where the neighbouring S6K1 and S6K2 genes were both deleted by a T-DNA insertion and rearrangement, shows sterility and aneuploidy (Henriques et al., 2010). This suggested a role for S6K in meiosis and chromosome segregation during 
male and female gametogenesis and in somatic cells. Investigating the mechanism behind this mitotic defect led to the discovery that S6K1 interacts with RBR and E2FB proteins, and required for the nuclear localisation of RBR (Henriques et al., 2010). To find out the physiological relevance for this molecular interaction, S6K1 was silenced in cultured cells grown with or without sucrose. While cell division was completely inhibited without sucrose, the S6K1-silenced cells continued to divide, showing that under nutrient starvation conditions, S6K1 functions as a repressor of cell proliferation (Henriques et al., 2010). Further supporting the repressor function of S6K1 in cell division that it downregulates E2FB protein level, while E2FB negatively regulates S6K protein level and activity (Henriques et al., 2013). Such double negative loops are characteristic of molecular switches, this particular S6K1-RBR-E2FB circuit could serve to repress cell proliferation upon energy exhaustion, which can be reversed to induce cell proliferation upon sucrose availability, when the TOR-S6K pathway is activated (Fig 1B; Henriques et al., 2014).

\section{Control of G2/M progression by the TOR pathway}

The TOR signalling pathway is most often discussed as a regulator for G1/S transition, however studies on other organisms suggest that TORC1 components also have function at the onset of mitosis (Fig 2; Atkin et al., 2014). In fission yeast there are two TOR proteins; Tor1 and Tor2, which form two distinct complexes TORC2 and TORC1, respectively. The Tor1-centred pathway is facilitating the cell growth under nutrient-limited conditions, meanwhile the Tor2 signalling is responsible for vegetative growth by controlling the G1/S transition. The nutrient dependent mitotic entry is mediated through Tor1 signalling and the stress response MAP kinase pathway involving Sty1, leading to changes in the activity of the mitotic kinase Cdc2 (Petersen and Nurse, 2007). In budding yeast, either treating cells with rapamycin or introducing a temperature-sensitive allele of raptor (a conserved regulatory partner of TOR), resulted in mitotic delay with a prolonged G2 phase (Nakashima et al., 2008). In synchronised human cell lines, it was shown that raptor is mitotically phosphorylated on multiple phospho-sites and required for normal G2/M transition, since ectopic expression of phospho-mutant raptor caused G2/M delay (Ramirez-Valle et al., 2010). Interestingly, the mitotic CDK1-cyclinB complex was shown to be responsible for the phosphorylation of RAPTOR during M-phase in yeast (Gwinn et al., 2010).

In plants, our understanding of TOR signalling in M-phase control is yet to be cemented. The recent finding that TOR regulates cell cycle progression through the SMR class of CDK inhibitor proteins hints that this might have both $\mathrm{G} 1 / \mathrm{S}$ and $\mathrm{G} 2 / \mathrm{M}$ inputs (Fig 2; Barrada et al., 2019), because the SMRs were shown to act both on CDKA;1 with RBR as a major target and the mitosis-specific CDKB1;1 (Kumar et al., 2015). There is also evidence to suggest that sucrose, a prevalent inducer of TOR, regulates the cell cycle differently at the G1/S and G2/M transitions. Silencing of RBR allows sucrose-deprived Arabidopsis cultured cells to enter into the cell cycle, but interestingly these RBR silenced cells were arrested later in the cell cycle at $G 2$ to $M$ phase transition (Hirano et al., 2008). This suggests that the downregulation of RBR can bypass the starvation-induced G1-, but not the G2-arrest. Similar observation was reported by Borghi et al. (2010) with RBR silenced (RBRi) Arabidopsis plants, where they showed increased number of cells with 4C DNA content in the leaf, suggesting a G2 arrest. Moreover, overexpression of CYCD3;1 in cell culture that 
leads to RBR inactivation also have an increased G2 cell cycle profile (Menges et al., 2006). These data collectively show that RBR acts on the G1/S transition to repress the cell cycle under sucrose-limiting conditions. What is the repression mechanism imposed by sucrose starvation at the G2/M phase is not yet known. It might also be possible that RBR have some non-canonical role at the G2/M progression to regulate chromatin structure, chromosome segregation or DNA repair (Dick et al., 2018; Horvath et al., 2017). On the mechanism of sucrose starvation-induced G2 arrest there are some clues coming from developmental regulators of shoot meristem activity. Skylar and colleagues reported that exogenous sucrose could revert the low activity of mitotic CYCB1;1::GUS and CDKB1;1::GUS reporters in the stip mutant (an allele of WUSCHEL-related homeobox 9; WOX9). Furthermore, sucrose induction rapidly repressed TPR-DOMAIN SUPPRESSOR OF STIMPY (TSS) transcription to rescue the stip mutant G2-arrested phenotype, suggesting that WOX9 regulates G2/M transition by suppressing TSS (Riou-Khamlichi et al., 2000). In another study, WOX9 was shown to interact with CYCP2;1, a cyclin that physically associates with three mitotic CDKs, and is required for the G2/M transition during meristem activation (Peng et al., 2014). Plants relay sugar availability largely through TOR pathway, thus it is possible that the WOX9-G2/M axis is functionally associated with TOR activation.

Expression of G1/S and G2/M phase specific genes are coordinated by the E2F and the Bmyb transcription factors, respectively (Magyar et al., 2016). Importantly, both these classes of transcription factors are together part of the multiprotein complex known as DP, RB-like E2F, and MuvB (DREAM) discovered in Drosophila and were later found in worm (DRM) and mammals. The DREAMs are repressor complexes containing multiple transcription factors besides E2Fs and Mybs (Sadasivam and DeCaprio, 2013).

Recently, DREAM-like complexes have been described in Arabidopsis (Fig 3; Kobayashi et al., 2015a, Kobayashi et al., 2015b, Magyar et al., 2016). Specific to plants is the existence of at least two distinct DREAM complexes, one with activator type transcription factors (E2FB and MYB3R4) and another with repressor types (E2FC and MYB3R3, Kobayashi et al., 2015a; Kobayashi et al., 2015b; Magyar et al., 2016). The activator complex can turn into repressor when cells exit cell-cycle, in this situation, E2FC and MYB3R3 respectively replace E2FB and MYB3R4 to inhibit expression of G2/M genes, establish quiescence and to achieve a differentiation state. Another function of the repressor DREAM complex in plants to repress mitotic genes outside of M-phase to ensure the waves of transcriptional activation in M-phase (Kobayashi et al., 2015b). In mammals, the assembly of the repressor DREAM complex is regulated by the dual specificity tyrosine-phosphorylation-regulated kinase $1 \mathrm{~A}$ (DYRK1A; Guiley et al., 2015). DYRK1A phosphorylates a subunit of MuvB, called LIN52, which is conserved among animals but have not yet been reported in plants. This phosphorylation event will serve as a signal to the DREAM complex to promote downregulation of cell cycle genes. Whether such regulation is operational in plants, and if it is involved in DREAM complex assembly or the interchange between activator and repressor type DREAM complexes on target genes, remains to be established.

Acceleration of cell cycle poses a threat of frequent of DNA damage, and to prevent passage of damaged genome to the next generations, cell cycle must be halted (Maya-Mendoza et al., 2018). Recovery from G2/M DNA damage checkpoint has been shown to dependent on TORC1 in human cells (Hsieh et al., 2018). TOR transcriptionally controls two of the most important mitotic genes, cyclin B1 and polo-like kinase 1 (PLK1) through regulation of 
histone lysine demethylase 4B (KDM4B). In Arabidopsis the upregulation of SMR-type CDK inhibitors and the stabilisation of repressor-type R1R2R3-Myb transcription factors were shown to suppress G2/M-specific genes to inhibit cell division in response to DNA damage (Chen et al., 2017). In addition, the RBR-E2FA complex was shown to localise on damaged heterochromatin foci and together they act as transcriptional repressor of the orthologue of the human breast cancer susceptibility gene 1 (Horvath et al., 2017). Biologically, it makes sense that RBR, being a master cell cycle regulator, also has a role in safeguarding the genome and thus ensuring genome integrity during proliferation. Whether the DNA damage response in plants is under TOR control is an open question.

\section{YAK1 emerged as a principal downstream target of TOR to regulate cell proliferation}

The DYRK family protein kinases are regarded as important regulators of cell cycle activity in yeast and animal cells (Becker, 2012; Soppa and Becker, 2015). For instance, DYRK2 negatively regulates S-phase entry, since depletion of its activity accelerated S-phase progression in human cells (Taira et al., 2012). Another DYRK family member is YAK1, which was actually the first member to be discovered through a genetic screen in search for negative growth regulators in Saccharomyces cerevisiae (Garrett and Broach, 1989). Initially in Arabidopsis YAK1 was reported to act as a positive mediator of abscisic acid (ABA) signalling in response to drought stress (Kim et al., 2015). ABA represses the expression of G1/S-phase genes like CDKA, CDC10 Target1 (CDT1A), TOPOISOMERASE I; and promotes the expression of CDK inhibitors such as KIP-RELATED PROTEIN 1 (KRP1), therefore $A B A$ signalling negatively regulates the cell cycle (Gutierrez, 2009). There is a direct connection between TOR and ABA pathways, as it was shown that TOR inhibits ABA signalling by phosphorylating the ABA receptor PYRABACTIN RESISTANCE 1-like 1 (PYL1). On the other hand, ABA represses TOR signalling by SnRK2-mediated phosphorylation of RAPTOR1 Fig 1A; (Wang et al., 2018). Further, since a DYRK family member is known to regulate the DREAM complex repressive function, it is templating to speculate whether TOR-regulated YAK1 signalling plays a role in modulating the activatoror repressor-type DREAM complex (Fig 3).

Recently a genetic screen for insensitivity to TOR inhibition provided compelling evidence for YAK1 to be a principal regulator below TOR to regulate root growth and meristem maintenance (Barrada et al., 2019). Loss-of-function YAK1 mutants are resistant to AZD8055 while YAK1 overexpressors are hypersensitive. YAK1 is essential for TOR-dependent transcriptional regulation of the SMR cyclin-dependent kinase inhibitors to restrict cell proliferation in the meristem. There is a possibility that YAK1 may act on TOR signalling through ABA as well as downstream of TOR to regulate cell cycle progression. Recently, a TOR phosphoproteomics study also uncovered YAK1 as a possible TOR target to be phosphorylated on at least two phosphopeptides (Van Leene et al., 2019).

\section{TOR-dependent translational control of the progression through the cell cycle}

Control at the translational level allows faster accumulation of the necessary cell cycle components compared with the regulation of transcription. The connection between the TOR-regulated translation initiation and cell cycle progression was first uncovered in budding yeast, where TOR was shown to be required for the elF-4E-dependent protein synthesis 
and, thereby, G1 progression in response to nutrient availability by enhanced translation of a G1 cyclin, CLN3 (Fig 2; Barbet et al., 1996). TOR also controls the proliferation of animal cells through selective translation of cell cycle regulatory genes, including cyclin D3 (Fig 2; Dowling et al., 2010). In agreement to these yeast and animal literature, a study using Arabidopsis cell culture showed that sucrose starvation induces the translational repression of genes enriched in cell cycle and cell growth (Nicolai et al., 2006). Diurnal regulation of translation also has large impact on the translational regulation of mRNAs including cell cycle regulators (Missra et al., 2015). Photomorphogenesis is another example accompanied by global changes in translationally controlled mRNA recruitment to polysomes (Liu et al., 2012; Liu et al., 2013). De-etiolating Arabidopsis seedlings undergo a rapid increase in translational capacity through phyA mediated repression of COP1, which acts negatively on auxin signalling. Upon COP1 inhibition, auxin-activated TOR induces the phosphorylation of the Ribosomal Protein S6 (RPS6) and it was suggested that this acts as a trigger for translation (Chen et al., 2018). However, the role of RPS6 phosphorylation by TOR-mediated S6K activation on translation is debated in yeast and animal literature, because mutating the phosphorylation sites on RPS6 has no effect on protein translation (Ruvinsky and Meyuhas, 2006; Yerlikaya et al., 2016). Interesting, RPS6 also have functions outside the ribosome as it was shown to associate with plant-specific histone deacetylase HD2 family members on rRNA gene promoters to regulate ribosome biogenesis (Kim et al., 2014). In animal cells $\mathrm{Rb}$ also have a role to regulate ribosome biogenesis through transcriptional repression of Poll and Pollll promoters (White, 2005).

Other components of the mRNA translation machinery have also been implicated in cell cycle regulation. The elF3h protein is part of the translation initiation complex, regulates the selective translation of mRNAs containing upstream open reading frames in their 5 ' UTR. elF3h activity is regulated by the TOR signalling through S6K1-mediated phosphorylation (Schepetilnikov et al., 2013). The eif3h mutant showed enhanced expression of WUSCHEL and CLAVATA3 in the apical shoot meristem, leading to over-proliferation and enlarged meristematic region, suggesting that eif3h provide a translational control in meristem maintenance (Zhou et al., 2014).

The ErbB-3 epidermal growth factor receptor binding protein (EBP1) is an evolutionary conserved growth regulator (Stegmann, 2018). In the plant field EBP1 came into the limelight as a dose dependent regulator of organ growth that in meristematic cells promote cell proliferation while in post mitotic cells it enhances cellular growth (Horvath et al., 2006). EBP1 was also identified as a potential gene involved in hybrid vigour. EBP1 expression is largely concentrated to the plant meristems and it was shown to be regulated by TOR (Deprost et al., 2007). Moreover, EBP1 expression shows strong co-regulation with a large group of genes having gene annotation of translational control, suggesting that EBP1 might enhance plant growth through this mechanism (Horvath et al., 2006). In animal cells EBP1 is localised to the nucleus, the nucleolus and the cytoplasm. In the nucleolus of human cells, EBP1, as part of ribonucleoprotein complexes, interacts with different rRNA species, therefore presumably plays a role in ribosome biogenesis (Squatrito et al., 2004). In the cytosol, EBP1 is associated with mature ribosomes and inhibits the stress-induced phosphorylation of the eukaryotic initiation factor 2 alpha (elF2a), therefore positively regulating the mRNA translation (Squatrito et al., 2006). In the nucleus, EBP1 physically binds to E2F1, Rb, histone deacetylase 2 (HDAC2) and Sin3A, therefore contributes to 
transcriptional repression of E2F targets and other growth regulator genes (Zhang et al., 2005). In contrast to animal cells, in plant cells EBP1 was shown to have a positive effect on cell proliferation and to positively regulate the expression of E2F target genes. In part, this might be through the downregulation of RBR protein level by EBP1.

Taken together, EBP1 and elF3h studies show the relevance of translation-dependent control of cell cycle progression in plants. The TOR-EBP1-RBR, TOR-S6K-S6 and the TORS6K-elF3h interactions are perhaps involved in matching and tuning cell growth with cell cycle progression both at the levels of translation initiation and ribosome biogenesis.

\section{Maintaining cell size homeostasis whilst cycling, the TOR connection}

Although cell growth (increase in size) and cell division (increase in cell number) are two separate processes with distinct regulation, but they are tightly coupled to maintain cell size homeostasis (Amodeo and Skotheim, 2016; Sablowski and Carnier Dornelas, 2014; Umen, 2018). TOR is the master regulator of protein synthesis (a driver of cell growth), but coupled to cell cycle regulation by multiple mechanisms. In fission yeast, deletion of Tor1 results in mildly larger cells under nutrient-rich growth conditions suggesting that TOR limits the onset of mitosis through MAPK signalling to allow more time for cell growth to occur and thus, increasing final cell size at division (Fig 2; Petersen and Nurse, 2007). In mammalian cell culture systems, blocking TOR using rapamycin leads to smaller cells regulated at both G1/S and G2/M points, but the effect is more pronounced at the former transition point (Fingar et al., 2004). The molecular basis of cell size regulation in cycling cells by TOR involves its well-conserved effector S6K1 activity 4E-BP1/eukaryotic translation initiation factor 4E (Fingar et al., 2004).

In Arabidopsis, overexpression of G1/S cyclin CYCD3;1 results in reduced cell size (Dewitte et al., 2003; Jones et al., 2017) phenocopied when E2FB expression is elevated in tobacco BY-2 cells (Magyar et al., 2005). In the Arabidopsis shoot meristem, mathematical modelling coupled with time-course microscopy work, it was reported that transition into both S-phase and M-phase is size-dependent (Jones et al., 2017), which is in agreement with the yeast studies. Additionally, increasing or decreasing CDK production, respectively, leads to smaller and larger meristematic cells. Thus, CDK activity drives size-dependent progression through the cell cycle. Considering that (i) RBR phosphorylation is the principal target of CDKA activity (ii) E2FB overexpression and RBR silencing results in reduced cell size, and (iii) E2FB is involved in the regulation of both $\mathrm{G} 1 / \mathrm{S}$ and G2/M transition, the TOR-YAK1-SMRCDKA-RBR-E2FB axis should be important to couple cell growth and cell cycle progression in the context of organ size control and cell size homeostasis. This might explain why E2FB, and not E2FA, can drive expression of both G1/S and G2/M genes and speed up cell cycle progression (Magyar et al., 2005).

\section{From TOR and cell cycle research to increasing crop yield}

Improving crop yield requires the understanding of molecular interactions and signalling pathways underlying plant growth and development. Overexpression of TOR results in 
bigger Arabidopsis plants (Deprost et al., 2007). Similarly, overexpression of one of the TOR target, EBP1 leads to increased organ growth both in Arabidopsis, potato and becomes upregulated by hybrid vigour ( $\mathrm{Li}$ et al., 2016a). More recently, Bakshi and colleagues ectopically expressed Arabidopsis TOR in rice and found that it increased growth and yield under water-limiting conditions (Bakshi et al., 2017). Furthermore, these transgenic rice lines showed insensitivity to ABA at the level of seed germination (Bakshi et al., 2017; Bakshi et al., 2019). Manipulating sugar signalling itself has also been reported to enhance crop yield. For instance, chemically spraying precursors of Trehalose-6-Phosphate (T6P) in Arabidopsis and wheat leads to increase yield and drought tolerance (Griffiths et al., 2016). T6P is thought to act as a signal for sucrose content (Wingler, 2018). Important future avenue is to effectively transfer the knowledge we gathered on TOR signalling to address important questions, such as identification of yield determining and yield stability factors connected to TOR in crop plants (Bakshi et al., 2019).

A. Cell cycle and cell growth are continuously adjusted to environmental signals (shown in red) such as sugar and light availability. Accordingly, TOR signalling cascade (shown in green) regulates the cell cycle through various signalling routes (shown in blue) and cell cycle regulators (shown in lilac). Light activates TOR by triggering phytochrome; phyA to inhibit the E3 ligase COP1, which negatively influences auxin-ROP2 signalling to TOR. The presence of sugars activate TOR, which results in the phosphorylation of E2F cell cycle transcription factors. TOR is also known to positively influence the transcription of EBP1, a regulator of cell and organ growth. At the protein level, EBP1 negatively regulates the cell cycle repressor RBR, and vice versa. EBP1 promotes CYCDs transcription, thus cell cycle entry. RBR in complex with E2FA represses transcription of endocycle genes in the meristem. S6K1 is the most widely known effector of TOR, and it may be involved in promoting translation of core cell cycle regulators such as CYCDs as in other model systems. ABA signalling promotes SnRK activity, the "yang" of TOR pathway. TOR counteracts $A B A$ response through phosphorylation of its receptor PYLs. This may result in promotion of cell cycle through counteracting the ABA-induced expression of CDK inhibitors (CKIs). YAK1 recently emerged as a principal downstream target of TOR to regulate cell cycle through the SMR type CDK inhibitors and as a regulator of ABA signalling.

B. The S6K1-RBR-E2FB module of the TOR network has a cell cycle repression function under sucrose starvation. Nutrient deprivation inactivates TOR signalling and S6K1. In its inactive state S6K1 promotes the nuclear localisation of RBR where it inhibits E2FB. S6K1 and E2FB negatively affect each other's protein stability. Thus, S6K1 also serves has a negative regulator of cell cycle.

\section{Figure 2. TOR - cell cycle regulation across the kingdoms}

TOR is a universal master regulator of cell growth in eukaryotes that connects to cell cycle regulation in various ways in different organisms. In fission yeast the nutrient dependent mitotic entry is mediated through Tor1 signalling and the stress response MAP kinase 
pathway involving Sty1, leading to changes in the activity of the mitotic kinase Cdc2 and mitotic entry. Upon nutrient starvation Gad8, an AGC kinase, is activated by Tor1 signalling to promote the arrest of mitotic cell cycle in $G 1$ phase therefore cells enter sexual development. In budding yeast, TOR regulates G1/S through promoting translation of $\mathrm{G} 1$ cyclin CLN3 and through de-stabilising SIC, a repressor of the CDK CDC28. TOR is also shown to regulate G2/M transition by promoting the nucleocytoplasmic translocation CDC5, a polo-like kinase. In mammalian cell lines, mTOR regulates translation of cell cycle regulators such as CYCD through its effector S6K1. TOR signalling is also required during mitosis since RAPTOR is mitotically phosphorylated by CDK1-CYCB complex. In Chlamydomonas, G1/S and G2/M transitions are controlled by E2F-DP association and CDKG1-CYCD dependent phosphorylation of RBR. Based on widespread cell cycle regulation by TOR signalling, this is likely to be under TOR contro. In Arabidopsis, TOR exerts its G1/S control through directly phosphorylating E2FA and allowing transcription of genes required for DNA replication. Recently, YAK1 was shown to be under TOR control. YAK1 negatively regulates cell cycle through CDK family of inhibitors, the SMRs.

\section{Figure 2. TOR to DREAM}

The multi-protein DREAM complex transcriptionally regulates progression and repression of cell cycle. Based on animal models, DRKY kinase regulate the DREAM complex assembly. Recently, a member of the DRKY kinase family, the Arabidopsis YAK1 was shown to be downstream of TOR, and a YAK1 phosphopeptide was found to be a target of TOR phosphorylation. This raises the possibility that YAK1 below TOR may regulate the behaviour of activator- and repressor-type DREAM complexes in a nutrient-dependent manner.

\section{Acknowledgments}

Z.A. is a recipient of BBSRC-DTP studentship (BB/M011178/1). L.B. and C.P. were funded by BBSRC-NSF grant BB/M025047/1. Z.M. was supported by the Hungarian Scientific Research Fund (OTKA NN-107838) and by the Ministry for National Economy (Hungary, GINOP-2.3.2-15-2016-00001). 


\section{References}

Amodeo AA, Skotheim JM. 2016. Cell-Size Control. Cold Spring Harb Perspect Biol 8, a019083. Atkin J, Halova L, Ferguson J, Hitchin JR, Lichawska-Cieslar A, Jordan AM, Pines J, Wellbrock C, Petersen J. 2014. Torin1-mediated TOR kinase inhibition reduces Wee1 levels and advances mitotic commitment in fission yeast and HeLa cells. J Cell Sci 127, 1346-1356.

Bakshi A, Moin M, Kumar MU, Reddy AB, Ren M, Datla R, Siddiq EA, Kirti PB. 2017. Ectopic expression of Arabidopsis Target of Rapamycin (AtTOR) improves water-use efficiency and yield potential in rice. Sci Rep 7, 42835.

Bakshi A, Moin M, Madhav MS, Kirti PB. 2019. Target of rapamycin, a master regulator of multiple signalling pathways and a potential candidate gene for crop improvement. Plant Biol (Stuttg) 21, 190-205.

Barbet NC, Schneider U, Helliwell SB, Stansfield I, Tuite MF, Hall MN. 1996. TOR controls translation initiation and early G1 progression in yeast. Mol Biol Cell 7, 25-42.

Barrada A, Djendli M, Desnos T, Mercier R, Robaglia C, Montane MH, Menand B. 2019. A TOR-YAK1 signaling axis controls cell cycle, meristem activity and plant growth in Arabidopsis. Development 146.

Becker W. 2012. Emerging role of DYRK family protein kinases as regulators of protein stability in cell cycle control. Cell Cycle 11, 3389-3394.

Berckmans B, Lammens T, Van Den Daele H, Magyar Z, Bogre L, De Veylder L. 2011. Lightdependent regulation of DEL1 is determined by the antagonistic action of E2Fb and E2Fc. Plant Physiol 157, 1440-1451.

Bisova K, Zachleder V. 2014. Cell-cycle regulation in green algae dividing by multiple fission. J Exp Bot 65, 2585-2602.

Borghi L, Gutzat R, Futterer J, Laizet Y, Hennig L, Gruissem W. 2010. Arabidopsis RETINOBLASTOMARELATED is required for stem cell maintenance, cell differentiation, and lateral organ production.

Plant Cell 22, 1792-1811.

Braybrook SA, Kuhlemeier C. 2010. How a plant builds leaves. Plant Cell 22, 1006-1018.

Chen G-H, Liu M-J, Xiong Y, Sheen J, Wu S-H. 2018. TOR and RPS6 transmit light signals to enhance protein translation in deetiolating \&lt;em\&gt;Arabidopsis\&lt;/em\&gt; seedlings. Proceedings of the National Academy of Sciences 115, 12823.

Chen P, Takatsuka H, Takahashi N, Kurata R, Fukao Y, Kobayashi K, Ito M, Umeda M. 2017.

Arabidopsis R1R2R3-Myb proteins are essential for inhibiting cell division in response to DNA damage. Nat Commun 8, 635.

Deprost D, Yao L, Sormani R, Moreau M, Leterreux G, Nicolai M, Bedu M, Robaglia C, Meyer C. 2007. The Arabidopsis TOR kinase links plant growth, yield, stress resistance and mRNA translation. EMBO Rep 8, 864-870.

Dewitte W, Riou-Khamlichi C, Scofield S, Healy JM, Jacqmard A, Kilby NJ, Murray JA. 2003. Altered cell cycle distribution, hyperplasia, and inhibited differentiation in Arabidopsis caused by the D-type cyclin CYCD3. Plant Cell 15, 79-92.

Dick FA, Goodrich DW, Sage J, Dyson NJ. 2018. Non-canonical functions of the RB protein in cancer. Nat Rev Cancer 18, 442-451.

Dobrenel T, Caldana C, Hanson J, Robaglia C, Vincentz M, Veit B, Meyer C. 2016. TOR Signaling and Nutrient Sensing. Annual Review of Plant Biology, Vol 67 67, 261-285.

Dóczi R, Hatzimasoura E, Farahi Bilooei S, Ahmad Z, Ditengou FA, López-Juez E, Palme K, Bögre L. 2019. The MKK7-MPK6 MAP Kinase Module Is a Regulator of Meristem Quiescence or Active Growth in Arabidopsis. Frontiers in Plant Science 10.

Dory M, Hatzimasoura E, Kallai BM, Nagy SK, Jager K, Darula Z, Nadai TV, Meszaros T, Lopez-Juez E, Barnabas B, Palme K, Bogre L, Ditengou FA, Doczi R. 2018. Coevolving MAPK and PID phosphosites 
indicate an ancient environmental control of PIN auxin transporters in land plants. FEBS Lett 592, 89102.

Dowling RJ, Topisirovic I, Alain T, Bidinosti M, Fonseca BD, Petroulakis E, Wang X, Larsson O, Selvaraj A, Liu Y, Kozma SC, Thomas G, Sonenberg N. 2010. mTORC1-mediated cell proliferation, but not cell growth, controlled by the 4E-BPs. Science 328, 1172-1176.

Ebel C, Mariconti L, Gruissem W. 2004. Plant retinoblastoma homologues control nuclear proliferation in the female gametophyte. Nature 429, 776-780.

Fingar DC, Richardson CJ, Tee AR, Cheatham L, Tsou C, Blenis J. 2004. mTOR controls cell cycle progression through its cell growth effectors $\mathrm{S} 6 \mathrm{~K} 1$ and $4 \mathrm{E}-\mathrm{BP} 1 /$ eukaryotic translation initiation factor 4E. Mol Cell Biol 24, 200-216.

Garrett S, Broach J. 1989. Loss of Ras activity in Saccharomyces cerevisiae is suppressed by disruptions of a new kinase gene, YAKI, whose product may act downstream of the CAMP-dependent protein kinase. Genes Dev 3, 1336-1348.

Gazquez A, Beemster GTS. 2017. What determines organ size differences between species? A metaanalysis of the cellular basis. New Phytologist 215, 299-308.

Griffiths CA, Sagar R, Geng Y, Primavesi LF, Patel MK, Passarelli MK, Gilmore IS, Steven RT, Bunch J, Paul MJ, Davis BG. 2016. Chemical intervention in plant sugar signalling increases yield and resilience. Nature.

Guiley KZ, Liban TJ, Felthousen JG, Ramanan P, Litovchick L, Rubin SM. 2015. Structural mechanisms of DREAM complex assembly and regulation. Genes Dev 29, 961-974.

Gutierrez C. 2009. The Arabidopsis cell division cycle. Arabidopsis Book 7, e0120.

Gutzat R, Borghi L, Futterer J, Bischof S, Laizet Y, Hennig L, Feil R, Lunn J, Gruissem W. 2011. RETINOBLASTOMA-RELATED PROTEIN controls the transition to autotrophic plant development. Development 138, 2977-2986.

Gwinn DM, Asara JM, Shaw RJ. 2010. Raptor is phosphorylated by cdc2 during mitosis. PLoS One 5, e9197.

Harashima H, Sugimoto K. 2016. Integration of developmental and environmental signals into cell proliferation and differentiation through RETINOBLASTOMA-RELATED 1. Curr Opin Plant Biol 29, 95103.

Henriques R, Bogre L, Horvath B, Magyar Z. 2014. Balancing act: matching growth with environment by the TOR signalling pathway. J Exp Bot 65, 2691-2701.

Henriques R, Magyar Z, Bogre L. 2013. S6K1 and E2FB are in mutually antagonistic regulatory links controlling cell growth and proliferation in Arabidopsis. Plant Signal Behav 8, e24367.

Henriques R, Magyar Z, Monardes A, Khan S, Zalejski C, Orellana J, Szabados L, de la Torre C, Koncz C, Bogre L. 2010. Arabidopsis S6 kinase mutants display chromosome instability and altered RBR1E2F pathway activity. Embo Journal 29, 2979-2993.

Hirano H, Harashima H, Shinmyo A, Sekine M. 2008. Arabidopsis RETINOBLASTOMA-RELATED PROTEIN 1 is involved in $\mathrm{G} 1$ phase cell cycle arrest caused by sucrose starvation. Plant Mol Biol 66, 259-275.

Horvath BM, Kourova H, Nagy S, Nemeth E, Magyar Z, Papdi C, Ahmad Z, Sanchez-Perez GF, Perilli S, Blilou I, Pettko-Szandtner A, Darula Z, Meszaros T, Binarova P, Bogre L, Scheres B. 2017. Arabidopsis RETINOBLASTOMA RELATED directly regulates DNA damage responses through functions beyond cell cycle control. Embo Journal 36, 1261-1278.

Horvath BM, Magyar Z, Zhang Y, Hamburger AW, Bako L, Visser RG, Bachem CW, Bogre L. 2006. EBP1 regulates organ size through cell growth and proliferation in plants. Embo Journal 25, 49094920.

Hsieh HJ, Zhang W, Lin SH, Yang WH, Wang JZ, Shen J, Zhang Y, Lu Y, Wang H, Yu J, Mills GB, Peng G. 2018. Systems biology approach reveals a link between mTORC1 and G2/M DNA damage checkpoint recovery. Nat Commun 9, 3982. 
Jones A, Forero-Vargas M, Withers SP, Smith RS, Traas J, Dewitte W, Murray JAH. 2017. Cell-size dependent progression of the cell cycle creates homeostasis and flexibility of plant cell size. Nat Commun 8, 15060.

Juppner J, Mubeen U, Leisse A, Caldana C, Wiszniewski A, Steinhauser D, Giavalisco P. 2018. The target of rapamycin kinase affects biomass accumulation and cell cycle progression by altering carbon/nitrogen balance in synchronized Chlamydomonas reinhardtii cells. Plant J 93, 355-376. Kim D, Ntui VO, Zhang N, Xiong L. 2015. Arabidopsis Yak1 protein (AtYak1) is a dual specificity protein kinase. FEBS Lett 589, 3321-3327.

Kim YK, Kim S, Shin YJ, Hur YS, Kim WY, Lee MS, Cheon CI, Verma DP. 2014. Ribosomal protein S6, a target of rapamycin, is involved in the regulation of rRNA genes by possible epigenetic changes in Arabidopsis. J Biol Chem 289, 3901-3912.

Kobayashi K, Suzuki T, Iwata E, Magyar Z, Bogre L, Ito M. 2015a. MYB3Rs, plant homologs of Myb oncoproteins, control cell cycle-regulated transcription and form DREAM-like complexes.

Transcription 6, 106-111.

Kobayashi K, Suzuki T, Iwata E, Nakamichi N, Suzuki T, Chen P, Ohtani M, Ishida T, Hosoya H, Muller S, Leviczky T, Pettko-Szandtner A, Darula Z, Iwamoto A, Nomoto M, Tada Y, Higashiyama T, Demura T, Doonan JH, Hauser MT, Sugimoto K, Umeda M, Magyar Z, Bogre L, Ito M. 2015b.

Transcriptional repression by MYB3R proteins regulates plant organ growth. Embo Journal 34, 19922007.

Kumar N, Harashima H, Kalve S, Bramsiepe J, Wang K, Sizani BL, Bertrand LL, Johnson MC, Faulk C, Dale R, Simmons LA, Churchman ML, Sugimoto K, Kato N, Dasanayake M, Beemster G, Schnittger A, Larkin JC. 2015. Functional Conservation in the SIAMESE-RELATED Family of Cyclin-Dependent Kinase Inhibitors in Land Plants. Plant Cell 27, 3065-3080.

Lastdrager J, Hanson J, Smeekens S. 2014. Sugar signals and the control of plant growth and development. J Exp Bot 65, 799-807.

Li JT, Yu G, Sun XH, Zhang XH, Liu JL, Pan HY. 2016a. AcEBP1, an ErbB3-Binding Protein (EBP1) from halophyte Atriplex canescens, negatively regulates cell growth and stress responses in Arabidopsis. Plant Science 248, 64-74.

Li X, Cai W, Liu Y, Li H, Fu L, Liu Z, Xu L, Liu H, Xu T, Xiong Y. 2017. Differential TOR activation and cell proliferation in Arabidopsis root and shoot apexes. Proc Natl Acad Sci U S A 114, 2765-2770.

Li Y, Liu D, Lopez-Paz C, Olson BJ, Umen JG. 2016b. A new class of cyclin dependent kinase in Chlamydomonas is required for coupling cell size to cell division. Elife 5, e10767.

Liu MJ, Wu SH, Chen HM, Wu SH. 2012. Widespread translational control contributes to the regulation of Arabidopsis photomorphogenesis. Mol Syst Biol 8, 566.

Liu MJ, Wu SH, Wu JF, Lin WD, Wu YC, Tsai TY, Tsai HL, Wu SH. 2013. Translational landscape of photomorphogenic Arabidopsis. Plant Cell 25, 3699-3710.

Lopez-Juez E, Dillon E, Magyar Z, Khan S, Hazeldine S, de Jager SM, Murray JA, Beemster GT, Bogre L, Shanahan H. 2008. Distinct light-initiated gene expression and cell cycle programs in the shoot apex and cotyledons of Arabidopsis. Plant Cell 20, 947-968.

Magyar Z. 2008. Keeping the Balance Between Proliferation and Differentiation by the E2F TranscriptionalRegulatory Network is Central to Plant Growth and Development. In: Bögre L, Beemster G, eds. Plant Growth Signaling. Berlin, Heidelberg: Springer Berlin Heidelberg, 89-105.

Magyar Z, Bogre L, Ito M. 2016. DREAMs make plant cells to cycle or to become quiescent. Curr Opin Plant Biol 34, 100-106.

Magyar Z, De Veylder L, Atanassova A, Bako L, Inze D, Bogre L. 2005. The role of the Arabidopsis E2FB transcription factor in regulating auxin-dependent cell division. Plant Cell 17, 2527-2541.

Magyar Z, Horvath B, Khan S, Mohammed B, Henriques R, De Veylder L, Bako L, Scheres B, Bogre L. 2012. Arabidopsis E2FA stimulates proliferation and endocycle separately through RBR-bound and RBR-free complexes. Embo Journal 31, 1480-1493. 
Maya-Mendoza A, Moudry P, Merchut-Maya JM, Lee M, Strauss R, Bartek J. 2018. High speed of fork progression induces DNA replication stress and genomic instability. Nature 559, 279-284.

Menand B, Desnos T, Nussaume L, Berger F, Bouchez D, Meyer C, Robaglia C. 2002. Expression and disruption of the Arabidopsis TOR (target of rapamycin) gene. Proc Natl Acad Sci U S A 99, 64226427.

Menges M, Samland AK, Planchais S, Murray JA. 2006. The D-type cyclin CYCD3;1 is limiting for the G1-to-S-phase transition in Arabidopsis. Plant Cell 18, 893-906.

Missra A, Ernest B, Lohoff T, Jia Q, Satterlee J, Ke K, von Arnim AG. 2015. The Circadian Clock Modulates Global Daily Cycles of mRNA Ribosome Loading. Plant Cell 27, 2582-2599.

Mohammed B, Bilooei SF, Doczi R, Grove E, Railo S, Palme K, Ditengou FA, Bogre L, Lopez-Juez E. 2018. Converging Light, Energy and Hormonal Signaling Control Meristem Activity, Leaf Initiation, and Growth. Plant Physiol 176, 1365-1381.

Montane MH, Menand B. 2013. ATP-competitive mTOR kinase inhibitors delay plant growth by triggering early differentiation of meristematic cells but no developmental patterning change. J Exp Bot 64, 4361-4374.

Nakagami H, Kawamura K, Sugisaka K, Sekine M, Shinmyo A. 2002. Phosphorylation of retinoblastoma-related protein by the cyclin $\mathrm{D} /$ cyclin-dependent kinase complex is activated at the G1/S-phase transition in tobacco. Plant Cell 14, 1847-1857.

Nakashima A, Maruki Y, Imamura Y, Kondo C, Kawamata T, Kawanishi I, Takata H, Matsuura A, Lee KS, Kikkawa U, Ohsumi Y, Yonezawa K, Kamada Y. 2008. The yeast Tor signaling pathway is involved in G2/M transition via polo-kinase. PLoS One 3, e2223.

Nicolai M, Roncato MA, Canoy AS, Rouquie D, Sarda X, Freyssinet G, Robaglia C. 2006. Large-scale analysis of mRNA translation states during sucrose starvation in arabidopsis cells identifies cell proliferation and chromatin structure as targets of translational control. Plant Physiol 141, 663-673.

Peng L, Skylar A, Chang PL, Bisova K, Wu X. 2014. CYCP2;1 integrates genetic and nutritional information to promote meristem cell division in Arabidopsis. Dev Biol 393, 160-170.

Perez-Perez ME, Couso I, Crespo JL. 2017. The TOR Signaling Network in the Model Unicellular Green Alga Chlamydomonas reinhardtii. Biomolecules 7.

Petersen J, Nurse P. 2007. TOR signalling regulates mitotic commitment through the stress MAP kinase pathway and the Polo and Cdc2 kinases. Nat Cell Biol 9, 1263-1272.

Pfeiffer A, Janocha D, Dong Y, Medzihradszky A, Schone S, Daum G, Suzaki T, Forner J, Langenecker T, Rempel E, Schmid M, Wirtz M, Hell R, Lohmann JU. 2016. Integration of light and metabolic signals for stem cell activation at the shoot apical meristem. Elife $\mathbf{5}$.

Ramirez-Valle F, Badura ML, Braunstein S, Narasimhan M, Schneider RJ. 2010. Mitotic raptor promotes mTORC1 activity, G(2)/M cell cycle progression, and internal ribosome entry site-mediated mRNA translation. Mol Cell Biol 30, 3151-3164.

Rexin D, Meyer C, Robaglia C, Veit B. 2015. TOR signalling in plants. Biochem J 470, 1-14.

Riou-Khamlichi C, Menges M, Healy JM, Murray JA. 2000. Sugar control of the plant cell cycle: differential regulation of Arabidopsis D-type cyclin gene expression. Mol Cell Biol 20, 4513-4521. Ruvinsky I, Meyuhas 0. 2006. Ribosomal protein S6 phosphorylation: from protein synthesis to cell size. Trends Biochem Sci 31, 342-348.

Sablowski R, Carnier Dornelas M. 2014. Interplay between cell growth and cell cycle in plants. J Exp Bot 65, 2703-2714.

Sadasivam S, DeCaprio JA. 2013. The DREAM complex: master coordinator of cell cycle-dependent gene expression. Nat Rev Cancer 13, 585-595.

Schepetilnikov M, Dimitrova M, Mancera-Martinez E, Geldreich A, Keller M, Ryabova LA. 2013. TOR and S6K1 promote translation reinitiation of UORF-containing $m$ RNAs via phosphorylation of elF3h. Embo Journal 32, 1087-1102. 
Schepetilnikov M, Makarian J, Srour O, Geldreich A, Yang Z, Chicher J, Hammann P, Ryabova LA. 2017. GTPase ROP2 binds and promotes activation of target of rapamycin, TOR, in response to auxin. Embo Journal 36, 886-903.

Schepetilnikov M, Ryabova LA. 2017. Auxin Signaling in Regulation of Plant Translation Reinitiation. Front Plant Sci 8, 1014.

Schepetilnikov M, Ryabova LA. 2018. Recent Discoveries on the Role of TOR (Target of Rapamycin) Signaling in Translation in Plants. Plant Physiol 176, 1095-1105.

Shi L, Wu Y, Sheen J. 2018. TOR signaling in plants: conservation and innovation. Development 145. Soppa U, Becker W. 2015. DYRK protein kinases. Curr Biol 25, R488-489.

Sozzani R, Maggio C, Varotto S, Canova S, Bergounioux C, Albani D, Cella R. 2006. Interplay between Arabidopsis activating factors E2Fb and E2Fa in cell cycle progression and development. Plant Physiol 140, 1355-1366.

Squatrito M, Mancino M, Donzelli M, Areces LB, Draetta GF. 2004. EBP1 is a nucleolar growthregulating protein that is part of pre-ribosomal ribonucleoprotein complexes. Oncogene $\mathbf{2 3}, \mathbf{4 4 5 4 -}$ 4465.

Squatrito M, Mancino M, Sala L, Draetta GF. 2006. Ebp1 is a dsRNA-binding protein associated with ribosomes that modulates elF2 alpha phosphorylation. Biochemical and Biophysical Research Communications 344, 859-868.

Stegmann M. 2018. EBP1: A crucial growth regulator downstream of receptor kinases across kingdoms. PLoS Biol 16, e3000056.

Taira N, Mimoto R, Kurata M, Yamaguchi T, Kitagawa M, Miki Y, Yoshida K. 2012. DYRK2 priming phosphorylation of c-Jun and c-Myc modulates cell cycle progression in human cancer cells. J Clin Invest 122, 859-872.

Umen JG. 2018. Sizing up the cell cycle: systems and quantitative approaches in Chlamydomonas. Curr Opin Plant Biol 46, 96-103.

Van Leene J, Han C, Gadeyne A, Eeckhout D, Matthijs C, Cannoot B, De Winne N, Persiau G, Van De Slijke E, Van de Cotte B, Stes E, Van Bel M, Storme V, Impens F, Gevaert K, Vandepoele K, De Smet I, De Jaeger G. 2019. Capturing the phosphorylation and protein interaction landscape of the plant TOR kinase. Nat Plants 5, 316-327.

Wang P, Zhao Y, Li Z, Hsu CC, Liu X, Fu L, Hou YJ, Du Y, Xie S, Zhang C, Gao J, Cao M, Huang X, Zhu Y, Tang K, Wang X, Tao WA, Xiong Y, Zhu JK. 2018. Reciprocal Regulation of the TOR Kinase and ABA Receptor Balances Plant Growth and Stress Response. Mol Cell 69, 100-112 e106.

Wang X, Proud CG. 2009. Nutrient control of TORC1, a cell-cycle regulator. Trends in Cell Biology 19, 260-267.

White RJ. 2005. RNA polymerases I and III, growth control and cancer. Nat Rev Mol Cell Biol 6, 69-78. Wingler A. 2018. Transitioning to the Next Phase: The Role of Sugar Signaling throughout the Plant Life Cycle. Plant Physiol 176, 1075-1084.

Wood E, Nurse P. 2015. Sizing up to Divide: Mitotic Cell-Size Control in Fission Yeast. Annual Review of Cell and Developmental Biology 31, 11-29.

Wu Y, Shi L, Li L, Fu L, Liu Y, Xiong Y, Sheen J. 2019. Integration of nutrient, energy, light and hormone signalling via TOR in plants. J Exp Bot.

Xiong Y, McCormack M, Li L, Hall Q, Xiang C, Sheen J. 2013. Glucose-TOR signalling reprograms the transcriptome and activates meristems. Nature 496, 181-186.

Yerlikaya S, Meusburger M, Kumari R, Huber A, Anrather D, Costanzo M, Boone C, Ammerer G, Baranov PV, Loewith R. 2016. TORC1 and TORC2 work together to regulate ribosomal protein S6 phosphorylation in Saccharomyces cerevisiae. Mol Biol Cell 27, 397-409.

Yoshida S, Mandel T, Kuhlemeier C. 2011. Stem cell activation by light guides plant organogenesis. Genes Dev 25, 1439-1450.

Zhang Y, Akinmade D, Hamburger AW. 2005. The ErbB3 binding protein Ebp1 interacts with Sin3A to repress E2F1 and AR-mediated transcription. Nucleic Acids Res 33, 6024-6033. 
Zhou F, Roy B, Dunlap JR, Enganti R, von Arnim AG. 2014. Translational control of Arabidopsis meristem stability and organogenesis by the eukaryotic translation factor elF3h. PLoS One $\mathbf{9}$, e95396. 
A

B

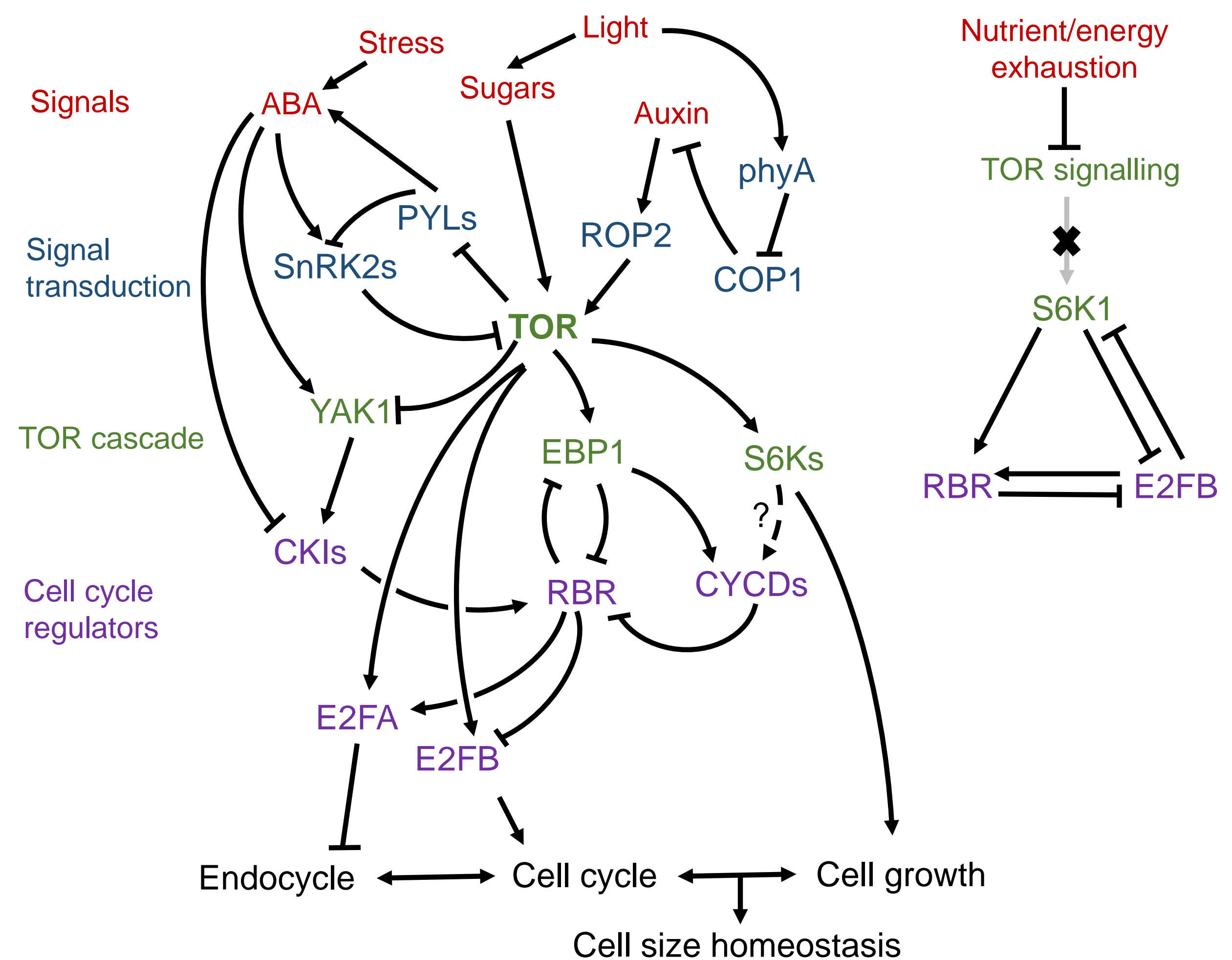




\section{Fission yeast}

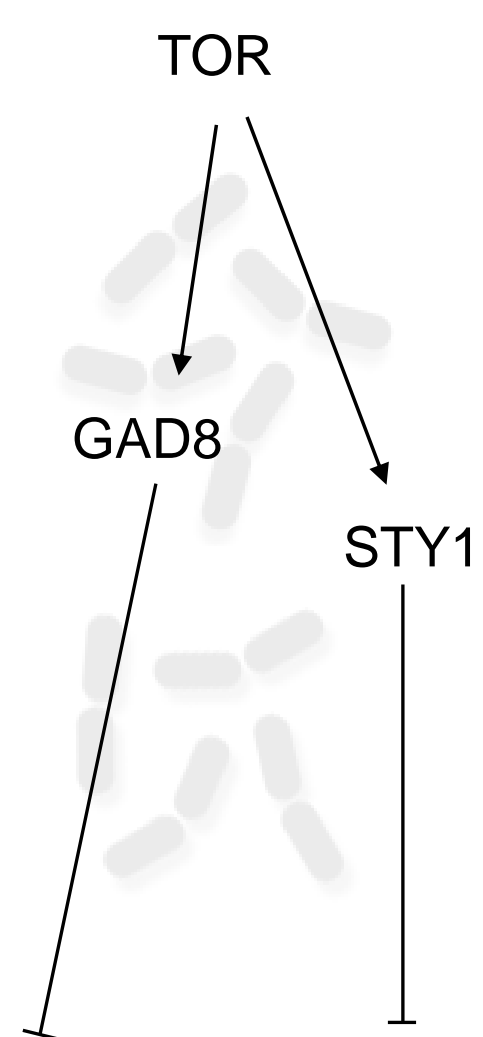

Budding yeast

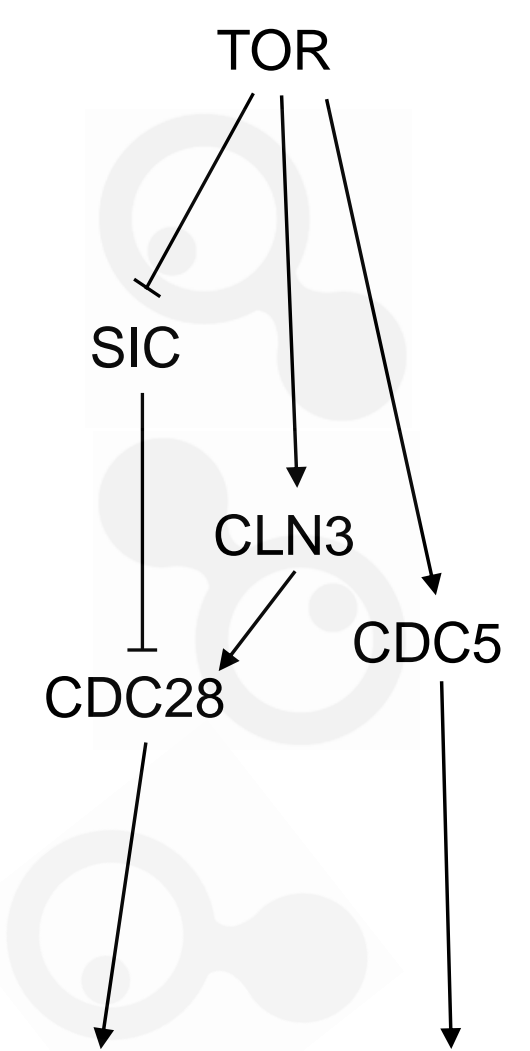

G1 S G2 M
Mammals

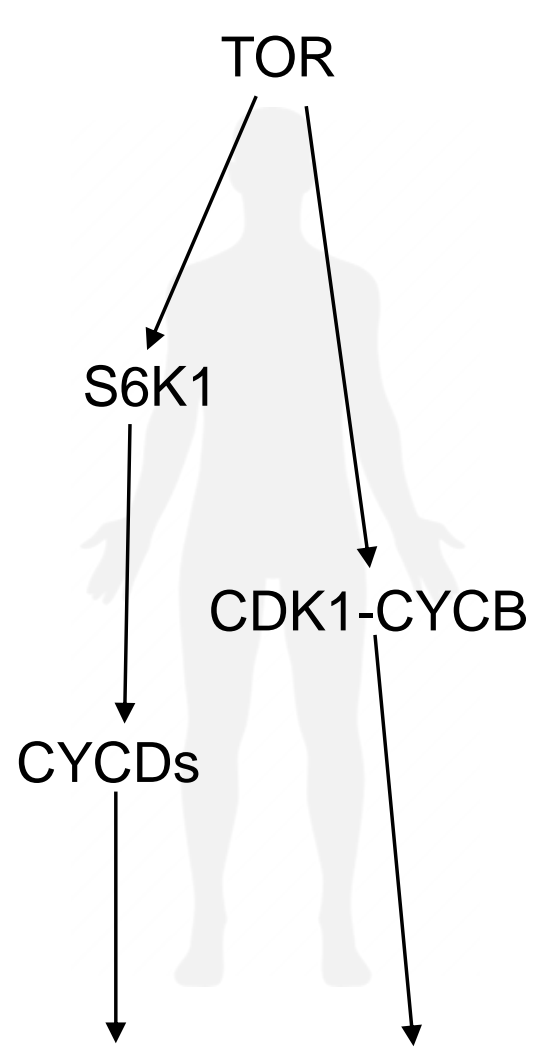

G1 S G2 M

\section{Chlamydomonas}
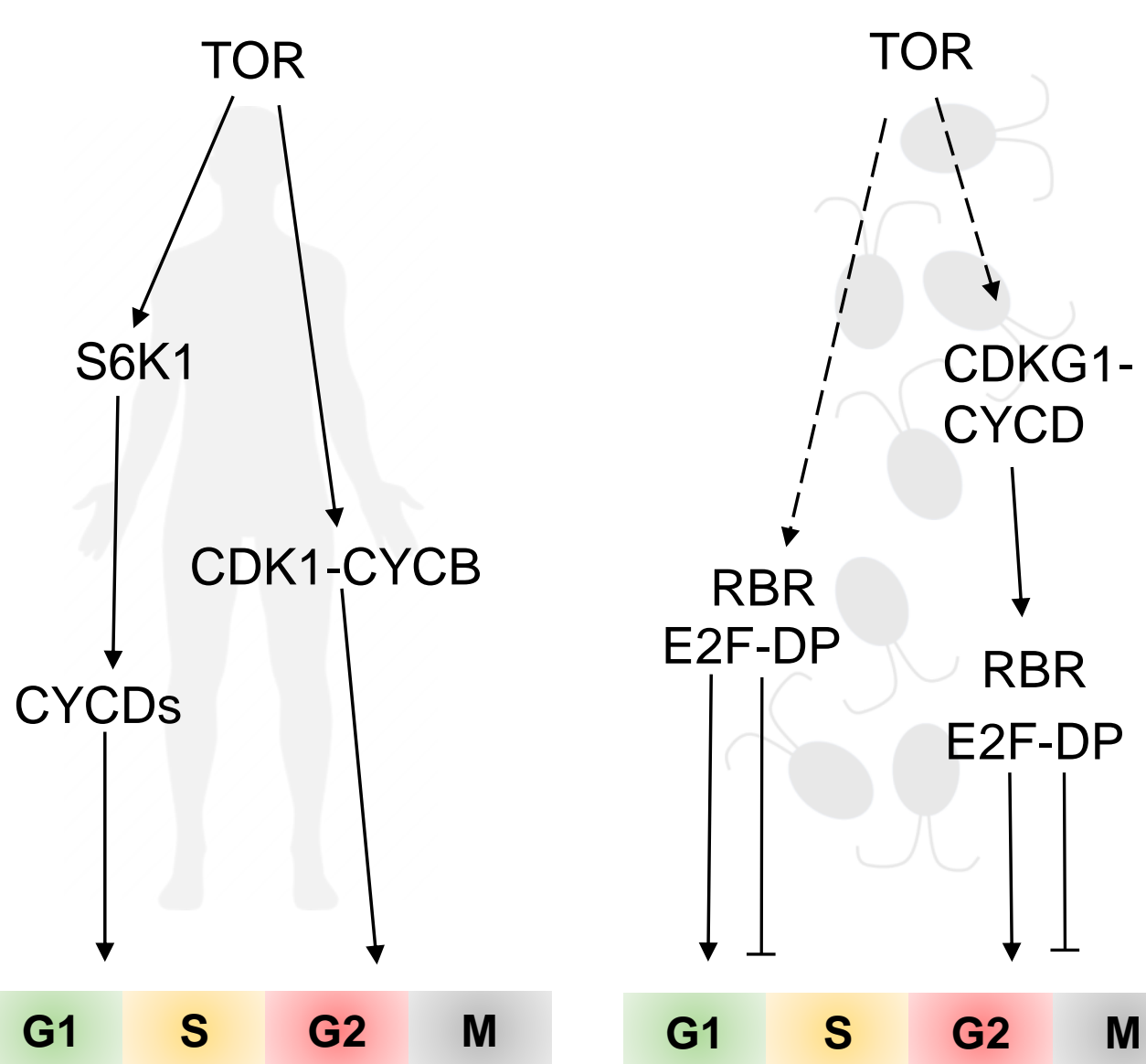

\section{Arabidopsis}

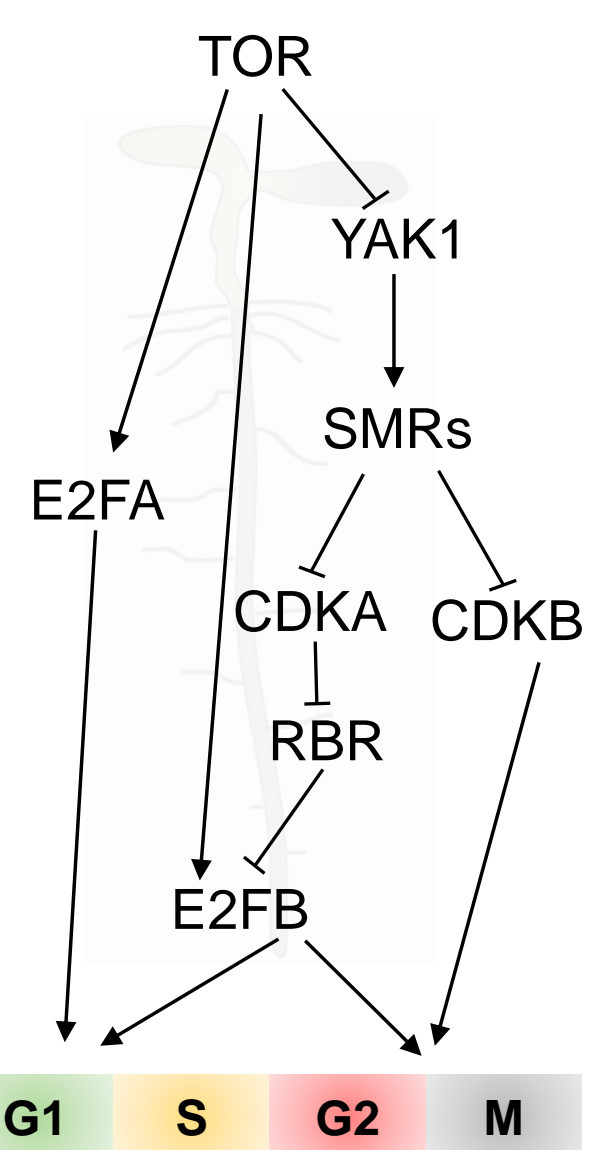


Figure 3

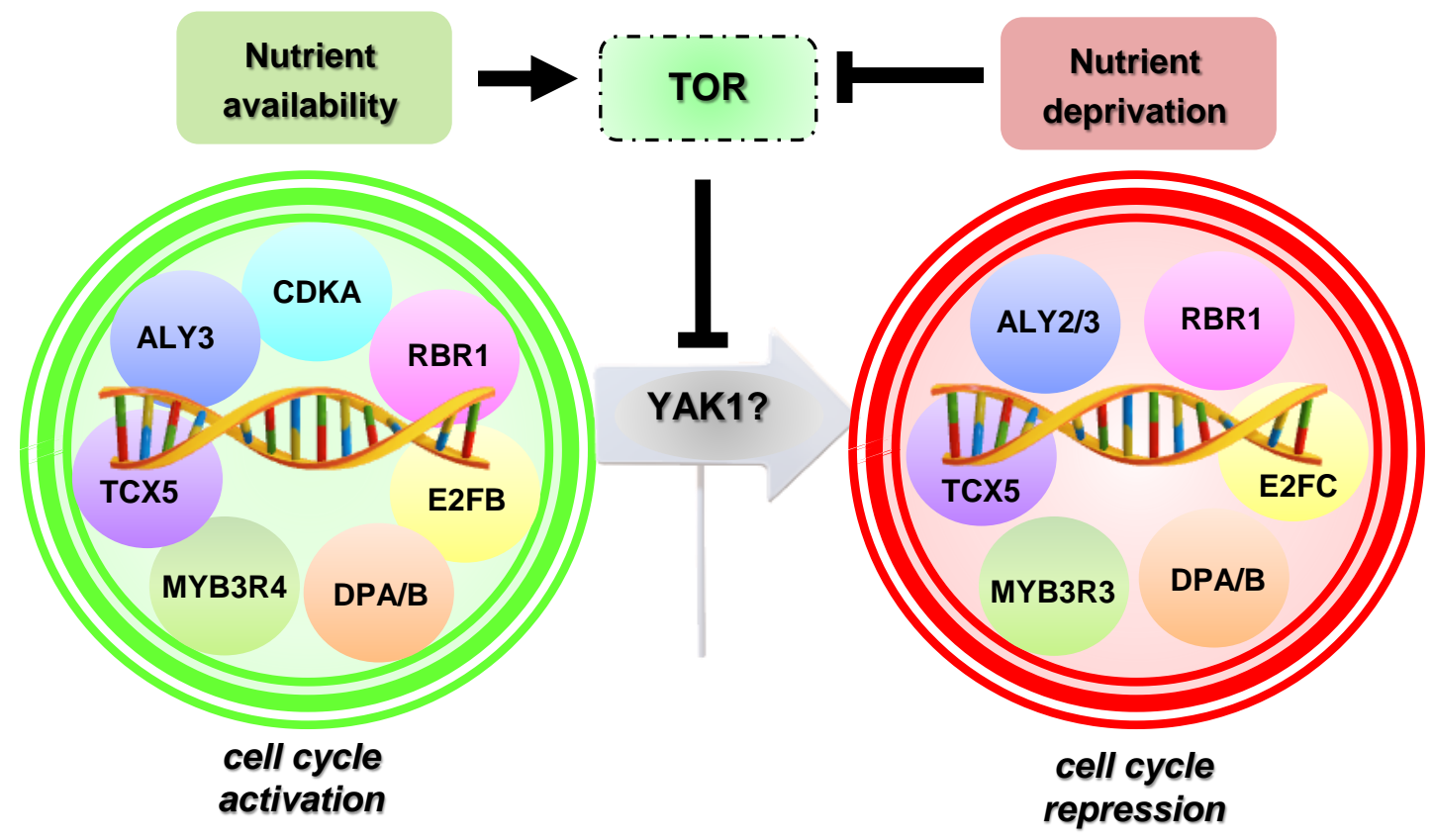

